\title{
Ciências Sociais e Saúde Coletiva: Novas Questões, Novas Abordagens
}

\section{Social Sciences and Public Health: New Issues, New Approaches}

\author{
Regina Cele de A. Bodstein'
}

BODSTEIN, R. C. de A. Social Sciences and Public Health: New Issues, New Approaches. Cad. Satide Pribl., Rio de Janeiro, 8 (2): 140-149, abr/jun, 1992.

This paper seeks to critically evaluate the paradigm that is still prevalent in the analysis of Health Policies within the academic production in the field of public health. In this sense, it starts from resuming the debate about the so-called crisis of the classic models in Social Sciences. This debate, influenced by several reviews of and criticisms to well-known theoretical schemes in sociology, accounts for both the enlargement of explanatory models and for the diversification of investigation issues and objects. It is therefore fundamental to consider the limits of the explanatory power of too generalizing theoretical models and, on the other hand, to give emphasis to the formation and action of collective subjects and actors, neglecting structuralizing approaches. This paper aims at showing the importance of this debate and its possible and necessary contributions for the academic production in the field of Social and Health Policies.

Keywords: Crisis of the Classic Models in Social Sciences; Health Policies; Social Sciences and Public Health

\section{INTRODUÇÃO}

Um balanço critico da produção no campo da saúde coletiva no Brasil, pelo viés de análise do Estado e das políticas de saúde, constitui-se numa tarefa necessária para o avanço desta temática. Depois de quase duas décadas de acúmulo de produção acadêmica, percebe-se, hoje em dia, um refluxo e um "esgotamento das energias utópicas" que gravitam em torno do campo (para utilizar uma feliz expressão de J. Habermas, 1987).

Importa perceber que esse balanço crítico deve partir de uma confrontação com o quadro analítico presente na maior parte dos estudos voltados para essa temática. Essa confrontação deve ser vista não como uma negação do conhecimento produzido, cujo mérito parece inquestionável, mas como o impulso necessário para se buscar novos problemas

\footnotetext{
'Departamento de Ciencias Sociais da Escola Nacional de Saude Pública. Rua Leopoldo Bulhões, 1480, Manguinhos, Rio de Janeiro, RJ, 21041-210, Brasil.
}

e novas abordagens.

Os limites impostos ao avanço do projeto reformista e democratizante na saúde, aliados à chamada crise do socialismo real, sem dúvida vem colocando diversos desafios quer aos policy-makers, quer ao espaço propriamente acadêmico de produção técnico-científica. No setor saúde, em particular (como também para a sociedade brasileira como um todo), é possível vislumbrar diversos paradoxos. O mais angustiante encontra sua raiz no fato de que, não obstante as conquistas populares e democráticas no plano jurídico-institucional, a qualidade e o acesso aos serviços de saúde, bem como as condições sanitárias da população, apresentam um desempenho negativo. A redemocratização do país sem dúvida alguma aguđizou questões como o corporativismo, o clientelismo e o fenômeno da privatização dos espaços públicos. Ou seja, apesar de uma considerável abertura do setor público, no sentido de uma maior participação de diversas instâncias da sociedade civil e das classes populares, e da modernização e descentralização da gestão do 
sistema, tais tendências mostram-se completamente ineficazes para deter o sucateamento da rede pública de serviços de saúde e fenômenos correlatos, como o crescimento avassalador da medicina de grupo e do seguro privado. É nesta perspectiva que adquire sentido a busca de novos marcos conceituais e a crítica aos referenciais teóricos já consagrados, dado o pequeno potencial explicativo daqueles usualmente utilizados.

Este artigo visa, ainda que de forma muito embrionária, apresentar o que seria o modelo explicativo clássico nas ciências sociais nas últimas décadas. Pretende-se apresentar suas limitações principais e suas fragilidades para, a partir daí, pensar sua influência nos estudos sobre Estado e políticas de saúde, temática tão cara para todos que trabalham no interior do campo da saúde coletiva.

\section{CRISE DOS MODELOS CLASSICOS E O DEBATE NAS CIÊNCIAS SOCIAIS.}

Tornou-se hoje, aqui no Brasil, praticamente lugar-comum falar em crise dos paradigmas na sociologia (Ianni, 1990). Na sociologia francesa, com sua longa tradição de vanguarda na produção teórica e nos debates acadêmicos, pelo menos desde os anos 70, vem sendo denunciada a chamada obsolescência das teorias clássicas (Castoriadis, 1986).

$\mathrm{Na}$ Alemanha, Claus Offe, inspirado no pensamento de Habermas, vem igualmente explicitando, por caminhos diversos, uma crítica à sociologia clássica ou, mais especificamente, uma crítica ao conceito, que bem ou mal, norteou todo o desenvolvimento do pensamento social: o trabalho como categoria sociológica chave (Offe, 1989a: 167).

Apesar da diversidade de enfoques, é forçoso reconhecer que o modelo tradicional de explicação sociológica está atualmente em discussão. Pretende-se aqui, dentro do possível, mostrar a centralidade desse debate hoje para o estudo das ciências sociais em saúde (e este é o ponto que se defende), devendo provocar impulsos de revisão crítica e um revigoramento das abordagens já consolidadas. Nessa medida, é uma reflexão inicial e certamente ainda precária, não tendo, por isso, a pretensão de trazer conclusões e definições acabadas.

Desde meados dos anos 60, surge na França uma polêmica entre dois conhecidos cientistas sociais, polêmica esta bastante divulgada, já que envolvia Althusser - teórico mais famoso dentro do pensamento político marxista no contexto Europeu. Do outro lado do debate encontra-se Touraine, um conhecido sociólogo, também de tradição marxista. A polêmica acirrada revela uma intensa luta política e teórica, traduzida em perspectivas bastante distintas sobre a contribuição marxista para a teoria social e política. No auge do debate, Touraine acusa Althusser de esmagar os fermentos da inovação por ordem da teoria (Touraine, 1969). Para ele, Althusser faz da teoria um camisa de força. A atividade teórica toma-se superior e independente da práxis. Em nome "dessa teoria", diz Touraine, são recusados estudos concretos sobre a realidade concreta. Cristaliza-se um conjunto de categorias responsáveis pela estrutura social, que ganha autonomia e procedência com relação à ação humana, à atividade dos sujeitos coletivos e, enfim, à história como produto da atividade humana. Segundo Touraine, e esta é a grande questão em discussão, ocorre com a teoria althusseriana uma substituição dos atores sociais pela noção de estrutura social. Os sujeitos e as classes sociais passam a ser vistos como suportes da estrutura. $\mathrm{Na}$ verdade, atores e classes são definidos na estrutura e através da estrutura, o que faz com que representem papéis já definidos prévia e anteriormente, de acordo com sua posição estrutural.

De certa forma, essa mesma questão está presente em outro célebre debate dos anos 70 , que envolve N. Poulantzas, de um lado, e R. Miliband, de outro. O ponto aqui é a teoria do Estado, de acordo com as diversas interpretações do legado marxista. De um lado, Poulantzas defende a pureza da teoria diante de contaminações empiricistas e a idéia das estruturas econômica, política e ideológica tal como formulada por Althusser.

Esses são alguns exemplos, entre tantos, que se poderia buscar envolvendo polêmicas semelhantes com protagonistas diferentes. $O$ que está em jogo desde então é uma interpretação determinista ou estruturalizante da dialética marxista. A partir desse marxismo estrutural, por exem- 
plo, é construída uma teoria do Estado que submete a política, a ação do governo e a formação de interesses a determinadas relaçōes de produção subjacentes (Cawson, 1986: 39). O estrutural, determinante em última instância, é sempre o nível econômico. No caso, o Estado é visto como um simples instrumento do capital para o exercício da dominação dos trabalhadores. Concede-se ao nivel político e ao Estado uma autonomia relativa - autonomia, apesar da determinação econômica, mas que, na verdade, mostra-se insuficiente para explicar certas conquistas em termos de direitos sociais. Como explicar a política social, em seu desdobramento e importância para os paises de capitalismo maduro, a partir desse esquema interpretativo?

Uma das noções mais arraigadas dentro dessa visão estruturalizante da teoria social é, como vimos, a concepção de que os homens atuam como agentes das estruturas. Contra essa noção, tão hegemônica dentro da sociologia dos anos 70 , emerge o pensamento de Touraine. Nesse combate contra o marxismo-estrutural e a sociologia clássica, representada por Tonnies, 0 autor produz, na primeira metade dos anos 80 , sua obra mais brilhante: o Regresso do Ator (Touraine, 1987). No livro, um libelo a favor de uma ciência social que recupere, como eixo central, categorias como ação, historicidade, movimentos sociais e representação política de demandas sociais (Touraine, 1987: 38), Touraine localiza nos clássicos duas tradições distintas, mas igualmente insuficientes de explicação sociológica. Primeiro, uma tentativa de se analisar os atores fora do sistema social, e a tendência oposta de se explicar o sistema sem a presença dos atores (1987: 17). Ele não se dispõe a trabalhar com a separação entre ator e sistema, mas pretende justamente enfatizar a inter-relação entre os dois termos, propondo, a partir daí, uma sociologia da ação social.

Não se trata aqui de apresentar, mesmo que de forma muito sintética, a proposta teórica de Touraine. Pretende-se tão somente apresentá-lo como um autor fundamental para a reconstrução do pensamento sociológico moderno, reconstrução essa que emerge a partir da crítica do marxismo estrutural (o sistema sem os sujeitos hitóricos concretos) e da teoria funcionalista em geral, de Talcott Parsons em particular (os atores e sua pluralidade de papéis, sem nenhum constrangimento sistêmico ou estrutural).

Castoriadis representa um outro expoente do pensamento crítico atual dentro das ciências sociais. Tal como Touraine, o autor traz uma riquíssima contribuição à teoria sociológica contemporânea, embora a partir de perspectivas distintas. Castoriadis desenvolve uma crítica profunda $e$ instigante sobre $o$ conjunto da produção sociológica e política de Marx, e aqui, também marcando sua diferença com Touraine, estende seu pensamento crítico para o próprio processo de produção de conhecimento e de teoria social.

$O$ autor vem, desde os anos 60 , construindo sua abordagem sociológica através de uma crítica da teoria marxista da história, da base epistemológica sobre a qual repousam seus princípios explicativos gerais e sobre o que o autor chama de "teoria fechada" (Castoriadis, 1986: 86). Merece destaque um aspecto metodológico importante na argumentação do autor. Para Castoriadis, o método, no sentido filosófico, é apenas o conjunto operante das categorias . O método não pode ser, assim, separado do conteúdo, especialmente quando se trata de uma teoria histórica e social (1986: 23). Na sua concepção, as categorias em função das quais pensamos a história são, de certa forma, essencialmente produtos reais do desenvolvimento histórico (1986: 24). Ou seja, ele quer enfatizar que, nas ciências sociais e na história, o método é afetado pelo desenvolvimento histórico real. Não porque ocorra um progresso do conhecimento ou novas descobertas científicas. A questão é outra. Diz respeito ao próprio objeto hitórico, que é um desdobramento de um mundo de significaçōes. Dessa forma, o sujeito do conhecimento histórico, como diz Castoriadis, vive num mundo de significações, a partir do qual ele entende e aprende a história. Neste sentido, não pode haver ruptura entre fato e sentido.

O curioso é observar que, em termos metodológicos, há muita semelhança entre sua crítica e o pensamento de Max Weber. Neste autor encontra-se também uma primazia do objeto sobre o método. Essa dependência do método em relação aos objetos de conhecimento é destacada por Weber, em sua polêmica com a chamada sociologia positivista de Comte e 
Durkheim. Para Weber, o método é uma técnica do conhecimento sendo comandada pela lei que rege toda a técnica, ou seja, pela sua eficácia. Nessa medida, diz ele, não existe um método ideal que garanta a validade do conhecimento cientifico. A validade da ciência e a opção por este ou aquele método dependem dos problemas específicos que o trabalho científico formula.

Uma questão relevante para Weber é a oposição entre o método naturalista e o método histórico, na medida em que, para o autor, os dois métodos utilizam de maneira diversa a noção de causalidade. No primeiro caso, no método naturalístico ou generalizante, como sublinha Weber, a seleção das causas se dá se os fenômenos se deixam subordinar a uma lei. Ou seja, a busca de leis ou de um princípio ou regra geral de classificação é, neste caso, um critério básico. Já para o método individualizante ou histórico, na concepção weberiana, a busca da regra geral ou da lei tende a apagar-se para deixar em evidência a unicidade qualitativa do devir. Ou seja, trata-se, neste segundo caso, de compreender, o mais objetivamente possivel, o sentido das ações humanas: como os homens avaliam, apreciam, utilizam, criam e destroem as diversas relações sociais (Freund, 1970: 70). Compreender, para Weber - e é disto que se trata quando estão em jogo as ciências da cultura -, é captar o sentido visado subjetivamente pelos agentes. Esse sentido subjetivo, por suas características intrinsecas, não pode ser explicado causalmente, mas deve ser compreendido.

No desenvolvimento da teoria social de Weber, essa distinção entre ciências naturais e humanas parece central. Ela revela sua contribuição específica para a construção da sociologia compreensiva, em oposição a Durkheim e aos positivistas em geral. O pensamento positivista nas ciências sociais, hegemónico em fỉns do século passado, tem em Durkheim sua grande expressão. Ele sustenta a existência de um método ideal e similar aplicado ao conjunto das ciências. O esforço analítico de Durkheim, considerado o fundador da sociologia como disciplina científica, é no sentido de mostrar que os fenômenos sociais, históricos e culturais se submetem ao método positivo, ou seja, aos cânones da ciência positiva. Dessa forma, os objetos das ciências sociais devem ser identifi- cados e analisados como coisas ou como fatos. Assim como os fenômenos naturais, os fatos sociais se desenvolvem quase que por si sós, obedecendo a uma dinâmica própria e praticamente externa e independente da participação do homem.

Ora, como procuramos mostrar, nada mais estranho para o pensamento sociológico de Weber do que essa ênfase na exterioridade dos fenômeno humanos (objeto da sociologia) em relação ao sujeito do conhecimento. Para Weber, ao contrário de Durkheim, a realidade objetiva não é exterior aos homens, mas impregnada dos significados das ações sociais que a construíram enquanto realidade objetiva social.

A ênfase na distinção entre as ciências da natureza e as ciências da cultura, e entre método generalizante e método individualizante, não significa, para Weber, que cada ciência utilizaria um dos métodos. Qualquer ciência, revela, utiliza os dois métodos. No caso das ciências da cultura ou sociais, ela opera necessariamente pela articulação dos dois métodos. Toda ciência humana procede por interpretação racional, ou seja, através da compreensão pela causalidade e pela compreensão a partir das relações significativas entre os fenômenos (Freund, 1970: 47). Para o autor, a explicação pelas leis gerais e a compreensão do significado são igualmente legítimas, e uma não pode prevalecer sobre a outra (Freund, 1970: 71). Não obstante, adverte, a análise causal, pelo aspecto exterior e objetivo do fenômeno, na busca de um princípio explicativo geral, se bem que necessária, não pode prescindir do outro nivel analítico, onde o que se busca é a especificidade do fenômeno e sua singularidade como realização da vontade humana. Segundo Weber, contentar-se com estudar a evolução de uma instituição unicamente no aspecto exterior, independente do que ela vem a ser pela ação do homem, é fugir a um aspecto capital da vida social. Efetivamente, o desenvolvimento de uma relação social se explica igualmente pelas intençōes que nela põe o ser humano, os interesses que nela encontra e o sentido diferente que ele the atribui no curso do tempo (Freund: 70).

Nessa perspectiva, o que se quer realçar no momento é a não exterioridade dos processos 
sociais em relação aos agentes sociais. Ao contrário, são impregnados dos significados e sentidos que os agentes thes atribuem. Os processos sociais são sempre legados já constituídos ou instituídos enquanto realizações historicamente já dadas. Mas o importante é perceber ou compreender, como diria Weber, as experiências e os sentidos que os atores concretos atribuem, aceitando/rejeitando ou reelaborando esses legados. A explicação compreensiva, o eixo do conhecimento sociológico para Weber, envolve o indivíduo e a coletividade, seres dotados de vontade, querer, devir, ilusões, consciência, inconsciência, racionalidade, etc. Daí, para o autor, a premissa básica das ciências da cultura: lidar com sujeitos/agentes que procuram assumir uma posição consciente face ao mundo, atribuindo-lhe um sentido (Freund, 1970: 97).

De forma resumida, o que se coloca como central na discussão sociológica hoje segue, em muito, a tradição weberiana de resgatar a explicação dos processos sociais pela dupla via: a partir do aspecto exterior, para além da intenção dos agentes sociais, sem com isso abandonar a dimensão da participação humana na formação e transformação das relaçōes e instituições sociais.

Não é outra a questão apontada por Castoriadis quando diz que não pode haver ruptura entre fato e sentido. Ora, o que seria fato senão aquela característica que os fenômenos apresentam de exterioridade, de autonomia e de contingência diante dos sujeitos históricos? $E$ sentido não é exatamente um atributo dos sujeitos enquanto agentes da história e do conhecimento histórico?

$\mathrm{Na}$ verdade, o que autores como Castoriadis e Touraine estão formulando, por caminhos diversos, bem entendido, é a crítica a um certo paradigma sociológico bastante predominante nas últimas décadas e que reduz os agentes, atores e classes sociais a instrumentos de uma força externa ou de um conjunto de leis originadas na estrutura ou no sistema social. Para Castoriadis, em particular, trata-se do paradigma marxista que define as classes sociais como encarnando a ação das forças produtivas. Se são atores, diz ele, São exatamente no sentido em que atores no teatro recitam um texto dado previamente e executam gestos predeterminados, e onde, representando bem ou mal, não conseguem impedir que a tragédia se encaminhe em direção a seu fim inexorável. O ponto nevrálgico para Castoriadis é que se, por um lado, Marx coloca as classes sociais como agentes do processo histórico, por outro, reduz as classes a agentes inconscientes sofrendo muito mais a ação do que agindo de fato (1982: 42).

No capitalismo, de acordo com Marx, a determinação do sistema encontra-se nas leis econômicas, ocorrendo o que Castoriadis classifica como um esmagamento da luta de classes em prol do determinismo econômico (1982: 43).

Ainda segundo Castoriadis, é necessário combater a visão das classes sociais e de sua ação como instrumento de leis e determinismos técnicos e econômicos. Diz ele: Se admitirmos que a tomada de consciência e a atividade das classes e dos grupos sociais (como individuos) fazem aparecer novos elementos não predeterminados e não predetermináveis (o que não significa que uma e outra sejam independentes das situações onde se desenvolvem), então seremos obrigados a sair do clássico esquema marxista e a encarar a história de uma maneira essencialmente diferente (1982: 45-46).

De qualquer modo, Castoriadis, tentando inovar criticamente o pensamento sociológico atual, realiza uma crítica intrínseca à teoria marxista, mostrando, entre outros pontos, como as classes sociais são transformadas a partir do marxismo em fatos, coisas e exterioridades.

Não obstante a enorme contribuição dada pelo próprio Marx e por alguns marxistas, questionando, entre outras coisas, o determinismo econômico $v i s-\dot{a}$-vis a recuperação da subjetividade, do nível individual e dos diversos agentes sociais, é necessário ter presente que isso se deu à custa de violentas e acirradas polêmicas.

Nessa perspectiva situa-se o historiador marxista inglês E. Tompson, que trouxe uma discussão bastante renovadora sobre as classes sociais, mas que foi profundamente criticado nos anos 70 por seu suposto empiricismo. Para o autor, classe não é uma estrutura nem uma categoria, mas um fato produzido pelos agentes e pelas relações sociais. Uma classe, diz Tompson, é fruto de uma experiência de vida comum quando alguns homens sentem e 
articulam uma identidade de interesses entre eles e contra outros homens cujos interesses são diferentes e freqüentemente opostos. Em outra passagem, diz o autor que se a experiência de classe aparece determinada a consciencia de classe não. Esta depende de como estas experiências são tratadas culturalmente. Nessa medida, classe é uma relação construída culturalmente e não uma coisa ou um fato exterior. Não se entende classe a não ser num processo de formação social e cultural (Thompson, 1982).

Uma outra crítica levantada por Castoriadis, mas igualmente presente entre alguns neomarxistas atuais, refere-se à superação das categorias até então utilizadas pela análise sociológica, já que não dariam conta da realidade sócio-histórica atual. Trata-se aqui de perceber que as novas configuraçōes e realidades sociais impõem novas categorias analíticas, como diz Touraine (1987: 51). De acordo com Castoriadis, aqui seguindo, como ele mesmo explicita, as pegadas de Marx, as categorias em função das quais pensamos a história são, por um lado, essencialmente produtos reais do desenvolvimento histórico (1986: 24). É por essa via que pensamos ser útil o reexame da teoria marxista, compreendendo por teoria a unidade entre categoria e método, como mostra Castoriadis.

Claus Offe, um expoente do pensamento neomarxista atual, propõe, por um lado, uma revisão do paradigma dominante na sociologia clássica e, por outro, uma leitura crítica da própria herança marxista. Na perspectiva analítica que aqui nos interessa, destaca esse autor o papel dos agentes e atores como mediadores entre estrutura e ação concreta. Em suas palavras, os esquemas analiticos tradicionais deixam de lado o papel dos agentes individuais $e$ seus estilos e reações. As estruturas não se traduzem diretamente em resultados e progressos; elas ofazem através das reações, interpretações, memórias e expectativas, crenças e preferências dos agentes que são mediadores entre estrutura e resultado. O recente ressurgimento de abordagens inetodológicas individualistas nas ciências sociais nos ajudou a recordar esse elo perdido na tradição de pesquisa macrossociológica (Offe, 1989a: 286).

Defendendo a incorporação de diversas con- tribuições teóricas como caminho frutífero para o desenvolvimento atual das ciências sociais, Offe acaba por inovar consideravelmente $o$ pensamento sociológico. Para ele, o capitalismo tardio e uma série de novos processos e questões a ele relacionados impōem uma revisão profunda das principais categorias sociológicas até então utilizadas.

Em suas palavras, $\boldsymbol{O}$ capitalismo tardio, com seus fenômenos de expansão e concentração, o surgimento do Estado intervencionista Benefactor e a progressiva burocratização de todos os âmbitos de interação social oferecem uma constelação de problemas que já não podem ser resolvidos com a fórmula geral dos processos de valorização capitalista (Offe, 1989b: 82).

Os estudos de Offe sobre o Welfare State e o capitalismo tardio trazem, em particular, uma série de revisōes sobre o paradigma de análise das políticas sociais. O pensamento do autor parece sobretudo instigante quando, em concordância com N. Bobbio, vê as profundas insuficiências da teoria política marxista (Offe, 1989b; Bobbio, 1983). Grosso modo e somente a título de ilustração, é conveniente destacar que para Offe, seguindo as pegadas de J. Habermas, o trabalho assalariado não seria mais um processo equalizador e homogeneizador, sobre o qual se elevaria ou se formaria uma consciência proletária. Não existiria, para ele, sequer uma única condição básica ou central que determinaria todas as demais. Nesse sentido, outros processos ou relacões sociais (entre consumidores, Homem/Mulher, Cidadão/Estado, etc...) não seriam menos relevantes e nem diretamente derivados da categoria "trabalho assalariado".

Na verdade, o Estado de bem-estar social, de inspiraçāo keynesiana, vem se colocando como mediador/administrador das desigualdades sociais. Trata-se, pois, de compreender a capacidade do Estado em administrar e distribuir os recursos da sociedade, de forma a contribuir para a realização e a garantia das noções prevalentes de justiça, assim como seus pré-requisitos evidentes, tais como o "crescimento econômico" (Offe, 1989a: 12).

Há pois fortes indícios de um deslocamento do espaço onde se desenrolam as lutas sociais atuais e dos atores e sujeitos históricos relevan- 
tes. É preciso reconhecer o espaço da cidadania moderna e o conjunto de seus sujeitos e de suas possíveis identidades como a mola propulsora atual dos novos movimentos sociais.

Fica clara a necessidade de se trazer para o interior do campo da saúde coletiva e das políticas sociais esse conjunto de questões. Tais questōes, que, sob alguns aspectos, parecem já antigas e superadas, têm ainda um efeito prejudicial para a teoria política marxista atual e, em particular, para as análises sobre a emergência e os efeitos das políticas sociais e do chamado Estado de Bem-Estar Social.

São bastante frequientes, nas grandes abordagens sobre os Welfare States, os estudos comparativos e a elaboração de macro-tipologias. Importa perceber que, a partir dessa dimensão, perde-se completamente de vista a dinâmica sócio-política, a conformação de sujeitos e o processo mesmo de negociação e decisão política que, na verdade, explicam a singularidade e a especificidade dos diversos processos de intervenção do Estado no social. Muito mais do que procurar os invariantes, o que se busca é a diferença, já que não há um modelo prévio de Estado de Bem-Estar a ser alcançado.

\section{PARADIGMA DOMINANTE NA ANALISE DAS POLÍTICAS DE SAÚDE E A BUSCA DE NOVOS REFERENCIAIS}

É possivel afirmar que as andilises sobre o Estado e as políticas de saúde no Brasil ganharam, a partir das duas últimas décadas, especificidade diante do conjunto das temáticas que compöem o campo da saúde coletiva. Tais análises, em particular, têm demonstrado um indiscutivel vigor, sendo responsáveis por boa parte da produção académica em torno da qual constituiu-se o campo da saude coletiva entre nós.

A partir da segunda metade dos anos 70 , consolidam-se algumas interpretações já clássicas para a problemática do capitalismo e da saúde no Brasil. Essas interpretaçōes constituem leitura obrigatória para todos que pretendam trabalhar no interior desse campo, e ponto de partida para o aprofundamento do debate atual sobre o setor saúde. Na verdade, pode-se dizer que é partir dessas análises que se estabelecem os fundamentos teórico-metodológicos que marcam o desenvolvimento do tema das políticas de saúde no país. Ou seja, esses estudos mapearam inicialmente as questões relevantes, gerando contundentes críticas ao sistema de saúde então vigente.

Apesar da diversidade de recortes, objetos e enfoques analíticos, é possível apontar um eixo comum em torno do qual gravita essa produção. No meu ponto de vista, ela é marcada por uma visão estrutural-determinista da teoria marxista, dominante também no conjunto das ciências sociais, como se pretendeu mostrar neste artigo.

Um dos referenciais explicativos mais presentes em tal literatura diz respeito ao papel instrumental da medicina para a reprodução da força de trabalho. É conveniente reconhecer que as condições de reprodução da força de trabalho são, acima de tudo, condiçôes culturais. Ou seja, não há como reduzir os aspectos subjetivos e experiências de vida a um suposto imperativo e determinismo econômico.

No caso específico das políticas sociais, ou melhor, do Estado e das políticas de saúde, privilegiava-se seu caráter funcional, quer para a acumulação de capital, quer para garantir a legitimidade do sistema. Acumulação e legitimidade constituem-se nas categorias-chave para explicar o funcionamento do aparelho estatal e, portanto, o conjunto das intervenções do Estado de corte social.

Esse paradigma, presente na literatura de forma explícita ou não, grosso modo, forma o quadro explicativo ainda hoje utilizado na produção em torno do tema. As análises mais empiricas que tentam reconstruir a política setorial e, portanto, enfatizam os atores em cena não escapam a esse esquema interpretativo. As consequiências do jogo político setorial na recomposição e definição de interesses e identidades sociais acabam sendo entendidas de forma unilateral: como funcionais aos interesses do capital.

É conveniente lembrar que, apesar da famosa autonomia relativa do Estado e, por tabela, da instância política, os processos e relaçōes sócio-históricas são vistos como apresentando uma determinação em última instância no econômico.

Duas observações prévias chamam a atenção. Em primeiro lugar, a funcionalidade ou instru- 
mentalidade do nivel político, do Estado e de seus aparelhos para o conjunto do sistema capitalista. Qualquer política específica, porque desenvolvida no interior de um Estado capitalista, acaba por fortalecer o processo de acumulação que passa a ser o eixo explicativo das políticas sociais. Ora, como mostrou Abranches (1985: 50), a acumulação dá os limites do processo político, mas não explica sua dinâmica. Finalmente, as categorias excessivamente generalizantes, como Estado, acumulação e legitimidade, têm o mérito, como aponta Maria Lucia Vianna, de dar sentido a tudo, sem explicar nada (Vianna, 1989: 153). O claro reducionismo do político no econômico, do especifico e particular no geral, ou, ainda, do empirico (realidade concreta) na teoria foram algumas das conseqüências da aplicação mecânica do paradigma estrutural-marxista. A própria categoria de Estado, central para a teoria política, aparece muito mais como um instrumento nas mãos da classe dominante, ou como cenário e local da luta de classes, do que como ator fundamental e decisivo para a implementação das políticas públicas.

Esse modelo explicativo não abre espaço para estudos que consideram o Estado como espaço político de tomada de decisões ou como o próprio núcleo das decisões. $O$ desempenho institucional do setor, seus avanços e recuos, só muito esporadicamente ganham destaque e análises especificas.

$O$ atrelamento da análise aos niveis estruturais acaba por condicionar as mudanças e inovaçōes políticas a transformaçōes metahistóricas: a derrubada do Estado ou a derrocada do sistema. O conflito político em torno das políticas redistributivas dos chamados novos movimentos da cidadania e das novas identidades culturais são quase que completamente subsumidos diante das "grandes transformações estruturais".

No caso da saúde, apesar da riqueza das abordagens sobre a medicina previdenciária $e$ seu crescimento avassalador às custas do setor privado-conveniado, deixou-se de lado uma questão fundamental que, a meu ver, avança na compreensão do problema. A massificação da assistência médica adotada no periodo militar politiza a questão médica de uma forma até então inédita no pais. Muito embora marcada pela ineficácia e ineficiência na gestão do setor saúde, essa massificação significa a inscrição da assistência médica curativa individual na agenda dos direitos da população urbana brasileira, até então praticamente excluída do cuidado médico-hospitalar. Esse processo, denominado pela literatura como "processo de extensão de sobertura" e tratado tecnicamente como tal pelos especialistas da área, foi, acima de tudo, um processo político cujas consequências e efeitos se fazem presentes até hoje. A assistência médica ou o conjunto dos serviços de saúde representam agora espaços visíveis de disputas de interesses, de organização de atores políticos em confronto, traduzindo um arranjo complexo de interesses, que não podem ser reduzidos a um único impasse entre Estado versus classes populares. Se é verdade que os serviços de saúde passam a ser objeto de demanda e reivindicações das classes populares, também é indispensável identificar os conflitos e processos que perpassam os diferentes segmentos de profissionais de saúde envolvidos numa diversidade de instâncias e práticas de saúde. Acentua-se, a partir da intervenção do Estado no cuidado médico, a emergência de novos interesses.e de novos conflitos, aparecendo o Estado como mediador $\mathrm{e}$ viabilizador do direito à saúde.

O risco das interpretações de cunho estrutural é, portanto, de reduzir ou desqualificar esse conflito ou de ver tais inovaçōes como decorrência natural e previsivel do sistema. Nesse esquema, joga-se fora os atores, os sujeitos sociais que se definem não a partir de suas posições prévias na estrutura social, mas a partir das identidades e interesses que se constituem na prática política, no próprio processo de conflito.

As análises marxistas clássicas apresentam uma grande dificuldade em considerar a prática democrática como um processo de conflito, uma recriação contínua da política, uma criação ininterrupta de novos direitos, enfim, uma subversão contínua do estabelecido, como nos diz Chauí, na apresentação feita ao trabalho já clássico de Claude Lefort (1987: 11).

Observando a produção teórica em torno do papel do Estado e das políticas de saúde, percebe-se a ausência de várias instâncias de articulação entre Estado e processo de formação de interesses e de representação 
política, a constituição de atores coletivos, o processo de ampliação dos direitos sociais e de consolidação de espaços democráticos.

Grosso modo, é forçoso reconhecer, se se quer avançar no debate, a insuficiência desse paradigma calcado em explicações excessivamente generalizantes e remetidas ao nivel estrutural. Este é entendido sempre como determinante em última instância e funcional ao processo de valorização do capital ou à reprodução da força de trabalho. Além disso, quando transposto para a análise das políticas sociais, tal paradigma reduz as intervenções estatais a um conjunto integrado e coerente, enfím, a um sistema de regulação social isento de contradição e praticamente incapaz de gerar novos confrontos. Acentua-se muito mais a capacidade de dominação do sistema (como uma condição quase inexorável) do que a dominação como relação social, neste sentido, recriada continuamente.

Enfim, o que se postula é a necessidade de se recuperar as politicas sociais e de saúde enquanto relações entre sujeitos sociais. Segundo meu ponto de vista, dificilmente essa análise pade se esgotar num nível macrossociológico. A riqueza da análise parece estar na visão da política de saúde como uma relação por um lado historicamente construída, por outro como espaço possível de reconstrução, quer seja a partir de novos sujeitos, novos significados ou novos direitos.

\section{RESUMO}

BODSTEIN, R. C. de A. Ciências Sociais e Saúde Coletiva: Novas Questões, Novas Abordagens. Cad. Saúde Públ., Rio de Janeiro, 8 (2): 140-149, abr/jun, 1992.

Este artigo tem como objetivo avaliar criticamente o paradigma ainda dominante na análise das políticas de saúde, no interior da produção acadêmica do campo da saúde coletiva. Nesse sentido, parte-se da recuperação do debate em torno da chamada crise dos modelos clássicos nas ciências sociais. Este debate, inspirado em diversas revisões e críticas dos esquemas teóricos consagrados na sociologia, é responsável tanto pelo alargamento dos esquemas explicativos quanto pela diversificação das questões e objetos de investigação. Assim, torna-se fundamental, nessa discussão, atentar para os limites do alcance explicativo dos modelos teóricos excessivamente generalizantes e, por outro lado, dar maior ênfase ao processo de formação e de ação de sujeitos e atores coletivos, em detrimento de abordagens estruturalizantes. $O$ que se pretende, então, é mostrar a importância desse debate e seus possíveis e necessários desdobramentos para a produção acadêmica na área das políticas sociais e de saúde.

Palavras-Chave: Crise dos Modelos Clássicos em Ciências Sociais; Políticas de Saúde; Ciências Sociais e Saúde Pública

\section{REFERÊNCIAS BIBLIOGRÁFICAS}

ABRANCHES, S. H., 1985. Os despossuidos (crescimento e pobreza no país do milagre). Rio de Janeiro: Zahar.

BOBBIO, N., 1983. Qual socialismo? Discussão de uma alternativa. Rio de Janeiro: Paz e Terra.

BODSTEIN, R. C. de A., 1990. Estado de Bem-Estar Social e Cidadania: Questões para o debate sobre políticas sociais. Saúde em Debate, 30: 21-25.

BRAGA, I. \& GÓES DE PAULA, S., 1981. Saúde e Previdencia: Estudos de Politica Social. São Paulo: Hucitec.

CASTORIADIS, C., 1986. A Instituição Imaginária da Sociedade. 2! ed., Rio de Janeiro: Paz e Terra.

CAWSON, A., 1986. Corporatism and political theory. Oxford: Brasil Brackwell.

COHN, G. (org.), 1982. Weber (Sociologia). São Paulo: Ática.

DONNANGELO, C. \& PEREIRA, L., 1976. Saude $e$ Sociedade. São Paulo: Livraria Duas Cidades.

DURHAM, E. R., 1984. Movimentos sociais, a construção da cidadania. Novos Estudos Cebrap, 10: 24-30.

FAVERET FILHO, P. \& OLIVEIRA, P. J., 1990. A universalização excludente: reflexões sobre as tendências do sistema de saúde. Dados, 2 : 257-283.

FREUND, J., 1970. A Sociologia de Max Weber. Rio de Janeiro: Forense.

HABERMAS, J., 1987. A nova intransparência. Novos Estudos Cebrap, 18: 103-114.

HÉSIO, C., 1980. A Indústria da Saúde no Brasil. Rio de Janeiro: Graal. 
IANNI, O., 1990. A Crise de Paradigmas na Sociologia. Revista Brasileira de Ciências Sociais, 13: 90-100.

KOSIK, K., 1969. Dialética do Concreto. Rio de Janeiro: Paz e Terra.

LACLAU, E., 1986. Os novos movimentos sociais e a pluralidade do Social. Revista Brasileira de Ciéncias Sociais, 2: 41-47.

LEFORT, C., 1987. A Invenção Democrática. 2! ed., São Paulo: Brasiliense.

LUZ, T., 1979. As Instituiçōes Médicas no Brasil. Rio de Janeiro: Graal.

MINAYO, M. C. de S., 1989. Estrutura e Sujeito (uma reflexão sobre a práxis social no setor saúde). Seminário sobre Prática Cientifica. Rio de Janeiro: Fiocruz.

OFFE, C., 1989a. A Democracia Contra o Estado do Bem Estar. In: Capitalismo Desorganizado Transformaçōes Contemporâneas do Trabalho e da Política, São Paulo: Brasiliense. 1989b. Razão e Política. Entrevista de Claus Offe. Lua Nova/Cedec, 19: 81-106.

OLIVEIRA, J. \& FLEURY, S. M., 1986. (Im) Previdencia Social. 60 anos de História da Previdência no Brasil. Petrópolis: Vozes.

POSSAS, C., 1981. Saúde e Trabalho. A crise da Previdéncia Social. Rio de Janeiro: Graal.

SADER, E., 1988. Quando novos personagens entraram em cena. Rio de Janeiro: Paz e Terra.

SORJ, B., 1989. Crise e Horizonte das Ciências Sociais na América Latina. Novos Estudos, 23: 154-162.

THOMPSON, E., 1982. The Making of the English Working Class. Middlesex: Peguin Books.

TOURAINE, A. 1969. As perigosas ilusões de Louis Althusser. Ensaios Opiniäo, 57-61. Aires: Eudeba.

1987. El regreso del Actor. Buenos

VIANNA, M. L. W. \& SILVA, B. A., 1989. Interpretação e avaliação da Política Social no Brasil: uma bibliografia comentada. Economia e Desenvolvimento. A Política Social em tempo de crise: a articulação institucional e descentralização. Vol. 3, Brasilia: Cepal. 